\title{
Research on Protection Approaches of Shanghai Islanding Historic and Cultural Landscape
}

\author{
Zhen Wei ${ }^{1}$ \\ ${ }^{1}$ Songjiang, Shanghai, 200335 \\ hunter2011@foxmail.com
}

\begin{abstract}
Keywords: Historical-Cultural Landscape Isolated Island, Classification, Protection, Shanghai, Landscape Architecture
\end{abstract}

\begin{abstract}
As an international metropolis, Shanghai has made remarkable achievements in urban construction, but in the history of landscape protection, she encountered many challenges and difficulties and all of those need to be addressed. For this purpose, this paper first proposed the concept of Shanghai Culture Island. With reference to the relevant national norms, history and culture of this independent silos system is classified and graded. According to the research of site study and relevant information on the status of historical and cultural landscape of islands, this paper conducted a careful analysis. And then put forward a comprehensive historical and cultural landscape conservation objectives, protection policies and protection methods, so as to expand the view of the innovation and effective protection approach for Shanghai historical and cultural protection.
\end{abstract}

\section{Introduction}

Shanghai is a modern developed city, nearly 20 years and gradually developed into an international metropolis, rapid economic development and urban construction. When Shanghai is on a large-scale urban construction, a section thorough fare intertwined, a skyscraper scale than the second section, the Shanghai's historical and cultural heritage has been gradually eroded and submerged. As cultural symbols and language, Shanghai local historical and cultural heritage has been in texture urbanization among complementary connected, isolated standing as an island state.

The formation of the historical and cultural landscape islands affected by five general areas:... A state of conservation security unit body, 2 internal coordination elements, 3 traffic conditions, 4 coordination with the surrounding architectural use of functional, 5 and. coordination of the surrounding environment. Security units to protect the body does not get better, will lead to cultural protection units to be assimilated surrounding environment, corrosion, missing state appears semi-formed historical landscape island. Uncoordinated internal element is one of the considerations in the history of the formation of the landscape islands. As in the ancient ruins, the protection of pagodas temples and other cultural protection unit, the multi-use renovation, the way the expansion and in the process, sometimes ignoring the coordination of security units inside the element, causing the body inside their isolation, forming islands condition. Also, do not reach sexual security unit of traffic or intricate aspect surrounding transportation network, but also caused its split situation in the urban fabric, the formation of historical landscape island. . Cultural protection units and the surrounding buildings uncoordinated use features, resulting in isolated historical protection unit, forming an island state. Modern environmental protection units are among the skyscrapers, will lead to security unit to be isolated, while weakening its historical landscape value, uncoordinated landscape visuals are formed on the boundary of the city day.

\section{The Distribution and Classification of Shanghai Historical and Cultural Landscape Islands}

Shanghai history and culture landscape islands, from density is concerned, most of the islands are concentrated in the central city, especially Huangpu District, Jingan district is particularly concentrated in Puxi more concentrated. In the distribution of the old town has a T-shaped structure. Old Town is the center, surrounded by a all starts. The most eastern head are Chongming District, 
Pudong New Area, Jinshan District, Fengxian District. The most western end are Baoshan District, Jiading District, Qingpu District, Songjiang District. Shanghai historical landscape islands formed mainly distributed in the central city structure "belt and point" combinations. By the Huangpu District as the center, to the Hongkou District, Zhabei District, Jing'an District, Pudong New Area, bearing radioactive zonal distribution, the formation of three branches to type, surrounding a dot dispersed layout. Huangpu District east from the Bund, historical landscape islands bearing strip diffuser to Jing'an District. Meanwhile, the Wusong Road, Huangpu District began bearing linear distribution to the Hongkou District.

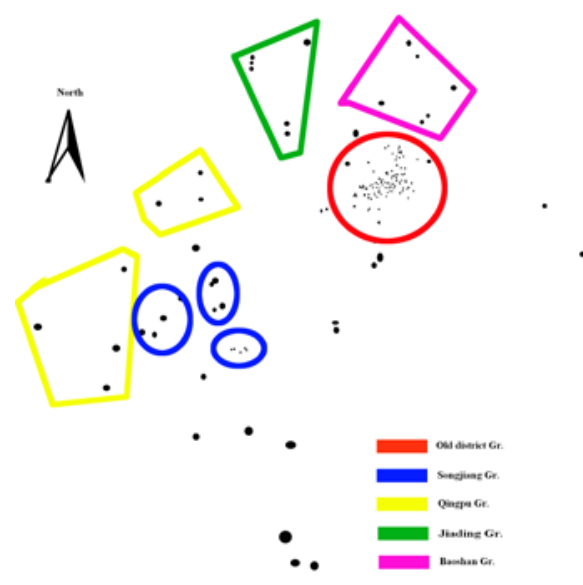

Fig. 1 Shanghai historical and cultural landscape islands scatter density distribution diagram

Center city conservation units considered concentrated, while the city outskirts and historical landscape is relatively fragmented islands. Old Town is the center, surrounded by the new city into Zhongxinggongyue trend. In the suburbs of major cities and towns in Qingpu District, Jiading District, Baoshan District, more concentrated. The most eastern head of Chongming District, Pudong New Area, Jinshan District, Fengxian District. The most western end of Baoshan District, Jiading District, Qingpu District, Songjiang District. The new city is mainly characterized by overall dispersion, structural features locally concentrated. Metro areas were clusters each state, but also more dispersed among the various groups within the region.

\section{Situation Analysis of Shanghai History and Culture Landscape Islands}

Shanghai historical and cultural landscape islands existing protection status, some protection is good, some poor protection, some almost ignored. Some of the space inside the protection is good, the overall protection is more complete, but the surrounding environment and traffic accessibility is rather poor, but some sites within the body of cultural relics protection is insufficient and the surrounding environmental protection are also relatively poor. It can be divided into the following three categories:

(A) Protect the historical landscape main islands, it has been built museums, public visiting the base and other public buildings, open for public visit, has great historical significance of education. These Shanghai historical landscapes are about 126 islands.

(B) The historical landscape islands body protection is better, but the basic is privately owned, not open, not reflected in historical memory and meaning obvious, its historical value is fading. These Shanghai historical landscapes are about 34 islands.

(C) The historical landscape islands improper body protection, use basic functions abandoned, historical memory symbols disappeared, the disappearance of the state in a semi-historical value greatly the loss of historical value and significance. These Shanghai has 22 historical landscape islands. 


\section{Shanghai Islanding Protection Principles of Cultural Historical Landscape}

Protection and Utilization of the islands, we should protect and use both, how to carry out the promotion of the use of the general principle of protection is to protect the use of. Therefore, the Shanghai Cultural Landscape islands as a system to study, in follow strong protection, rational use, based on the success of a similar comparison from abroad valuable experience, combined with the actual situation of Shanghai, to develop an island system complies with international and domestic standards of protection and utilization principles.

Adhere to the principle of authenticity. Islands of conservation planning should be kept Authenticity silos body and the surrounding environment. Repair old as to protect the original is a manifestation of the principle of authenticity. In short, the historical and cultural landscape of islands truly original site of the body, complete protection and restoration, to protect all of its legacy of historical information.

Follow the integrity, integrity principle. Historical and cultural landscape islands "solitary" word, so that the site where the body and the environment is relatively isolated existence, undermine symbiotic concept of harmony. Forming islands historical and cultural landscape sites, split with the surrounding environment, the historical value of the site will be lost or weakened, and some have been reduced to rubble. Not only reflected in the coordination body for the site, the surrounding environment.

Contiguous region, overall co-ordination of protection principles. Planning for protection of historical and cultural landscape of Shanghai islands, the islands of the system should focus on research in the area contiguous, overall co-ordination protection principle. Currently, the island state is their own business, historical and cultural value has gradually been lined with high-rise modern buildings surrounding the weakening of some islands has been gradually abandoned. Therefore, to solve the problem an island in its protection and utilization of the plan, it must follow the historical and cultural landscape now an island in the protection and utilization planning within the region even into the area to protect the principle of an island group in the overall co-ordination of the chip area.

Adhere to the principle of historical and cultural readability. Shanghai historical and cultural landscape islands represent a historical story, legend, people can read the law they are "historical ring" and evolution directly from historical blots. These islands represented the art technology, superb culture, they have a priceless value readability. Of course, the process in the city, with modern architecture and the environment to the erosion of historical and cultural landscape islands are in violation of the principle of readability.

Adhere to the principle of harmonization. Islands in conservation planning, we should adhere to the principle of harmonization. Inter-islands and the surrounding environment, or can coordination between contiguous group of islands interlinked and understanding of each part. Through the spatial structure, building materials, facade color, body mass scale, the construction technology to achieve an association to achieve harmonization principles. Whether this is a modern building, the site of the Restructuring or islands, part of the expansion, and the islands can form a harmonious whole, reaching necessarily linked.

\section{Shanghai Historic and Cultural Landscape Island Protection Strategy}

Strengthen the body interior protection of historical and cultural value amounts islands. Interior Protection Act is to protect heritage in a common way. Miyagi Prefecture, Japan Hiraizumi Jintang, built in AD 1124, after a complete renovation restored as indoor building, newly designed buildings with air conditioners and a shelter earthquake and fire facilities, visitors can watch through the glass. Built in 197 BC-195 BC, the ancient Greece Pajia Ma museum is protected.

The body of the local islands remaining half retained its integration into the new building or the environment. Some sites of historical and cultural landscape islands body has been destroyed, there is only a part of the site or a fragment, the residue off the local masonry in new buildings or integration of the environment through the art of processing forms part of the new 
environment, new buildings, can get moving shocking effect. Some islands have been in a semi-destroyed ruin of body condition, recovery is difficult to repair, only part of the ruins of the residual component and this model can also be used to deal with the historical and cultural landscape in Shanghai silos.

The islands heritage body and the surrounding environment classification of classified protection plan. In Shanghai the protection of historical and cultural landscape planning islands in the body and can be used to classify the surrounding environment of the protection division manner. It can be classified according to the morphology of the divided island spatial characteristics.

According to material differences islands form geometric space can be divided into point-like body and the surroundings islands heritage, linear heritage body and the surrounding environment, regions Heritage Site and the surrounding environment.

The establishment of the regional environmental protection of historical and cultural landscape islands. For the protection of historic and cultural landscape islands Shanghai, it should also be made to define the space surrounding environment, establish environmental protection area within the perimeter of scoping, change the "island" state. Surroundings islands should have historical and cultural information and values contained in the body sites islands, it is a derivative of an island site of the body. It can be roughly divided into "absolute protection area, the use of control areas, and environmental areas" in three parts. Absolute Sanctuary refers to the islands main buildings and ruins of the scope of land environment must be restored and the environment in accordance with authenticity, to "repairing the old". In absolute protection zone construction ban affects the islands historical and cultural features of buildings and structures. Using the control zone means in order to protect the integrity and security islands surrounding district sites controlled by the body must be, is an island of the second protection zone. Environmental coordination area refers to the second protection zone peripheral environment subdivide a line. Is an island and modern city landscape architectural space to achieve the transition zone and space.

\section{Shanghai Islanding Protection of Historical and Cultural Landscape Planning Methods}

Make Use of Detailed Planning and Design. In Shanghai the protection of historical and cultural landscape of islands on the basis of its re-use, you must first have a detailed comprehensive planning and design, this is carried out utilizing the basic guarantee islands premise. In the planning and design, the first to deal with the relationship between islands and the surrounding environment, the building; try to set excessive buffer zones, make convergence more natural. Planning adhere to the spirit authenticity, sustainability, and user-friendly design, increase the surrounding facilities. At the same time, pay attention to ecological islands, the original use of green trees to preserve, to replant the method, to create better visual landscape effect. Silos for larger flow of people, pay attention to the planning and design of human row, rational planning dealers flow lines, eye-catching logo design guides system with a strong historical and cultural symbols.

In the plan, in accordance with the guiding ideology of hierarchical planning to take advantage of the planning and design of historical and cultural landscape islands. Hierarchical planning requires that we strictly in accordance with the regulatory detailed planning, construction of detailed planning, landscape planning and design steps, step by step manner stepwise design.

The Implementation of Protection and Utilization of Funds. In Shanghai, protection and utilization of historical and cultural landscape of the island, the first prerequisite and guarantee is to ensure that there is adequate protection and utilization of funds. Therefore, establishing a sound financial protection mechanism is to implement the strong backing of funds costs. Learn from the experience of cultural relic protection, combined with the specific situation in Shanghai, we can ensure the following three aspects related to the conservation and utilization of funds: The Shanghai municipal government allocated special funds. Attract social and personal investment. Stimulate public participation, calling on private users to protect island restoration, encourage privately owned island protection, restoration and management. In the protection and management, you can use the new, diversified and multi-level channels to raise private funds to supplement funds for protection of the auxiliary national government funds to build a complete security system. 
The Establishment of Specialized Institutions. The establishment of specialized management agencies and organizations support professional management personnel, professional organizations to strengthen the intensity and extent of island protection and utilization of regulatory and grasp. Supervision islands specialized regulatory agencies can be refined to incorporate the effect of Shanghai cultural relics and protection regulations. Special management agency is responsible for the protection of historical and cultural landscape of islands, safety testing, management and utilization of services.

Develop the Shanghai Regulations of Historical and Cultural Landscape Islands. On the legal level, develop Shanghai Municipal People's Congress of historical and cultural landscape islands regulations, it is the protection and utilization of policy. Shanghai is to be formed to implement the protection of historic and cultural landscape islands use grading and repair management system. To ensure the integrity and security of islands, Shanghai security unit of the reference level of the islands are divided into national, municipal, district level, in accordance with the level of clarity of its protection and utilization regulations. Clear daily protection and utilization regulations. To prohibit littering the surround islands, to maintain the beauty of the surrounding environment. Protection of the surrounding greenery, landscaping. Development of protection and utilization of rewards and punishments detailed measures to encourage public supervision praise.

Efforts to Increase Public Participation. Shanghai large number of historical and cultural landscape of islands, the distribution is relatively insufficient gather, manage problems more difficult. Efforts should be made to increase public participation, and strengthen the people's awareness to protect, promote the concept of public participation. Public participation in the protection and utilization of historical and cultural landscape of the islands, referring to the mass society, social organizations, units or individuals to spontaneously form as a principal, social action within the scope of their rights and obligations in order to protect the historical and cultural landscape of islands for the purpose. On the one hand to improve the protection and utilization of all the people on the islands of public awareness of participation, while using an effective publicity to encourage public participation.

Advocate the Concept of Use for the Purpose of Protection. In order to take advantage of better protection, you can take now to encourage the use of the heritage of individual units to protect the principle of "no change does not destroy" There are many success stories abroad the historical and cultural sites is transformed into office space, public space, or space travel to use, thus avoiding the historical and cultural sites become an empty shell, the situation gradually been forgotten.

\section{Conclusion}

In this paper, Shanghai islands history and culture were discussed superficially, put forward constructive use planning guidelines and policies for protection. In future studies, we hope this paper can be taken as a base and further study on Shanghai historical landscape island can be produced. We should seize the time to rescue and protect these poor islands, make them glow former glory and to the benefit future generations.

\section{References}

[1] Q. Ye, M.Y. Wu. Urban Typology of Modern Design Methods to Protect Historical and Cultural Heritage, Chinese Gardens, 2014, Vol 2:17.

[2] G.Y. Yuan. Groups Dwelled Protection and Exploitation of Cultural Heritage-Kunming Historical and Cultural Cities Research and Reflection Protection, Humanities and Social Sciences, Yunnan University, 2001, Vol 27 (3): 52-57.

[3] J.H. Zhang, L.B. Gui. The City's Historical and Cultural Characteristics of the Environment Protection and Regeneration of Seoul City-Traditional Culture Protection in The Studyand Practice of Urban Planning, 2000, Vol 24 (11). 
[4] J. Zhang, C. Pang. On Surging Consumer Culture Cloning Urban Cultural Heritage, Urban Planning. 2009, Vol 6.

[5] Hewison, R .The Heritage Industry: Britain in A Climate of Decline London: Methuen, 1987

[6] James Marson. Fitch Historic Preservation: Curatorial Management of The Built World Newyork:. Megraw A Hill, 1982.

[7] Jan Vlcko, Vladimir Greif, Vladimir Grof, Michal Jezny, Lubomir Petro, Martin Brcek, Rock. Displacement and Thermal Expansion Study at Historic Heritage Sites in Slovakia, Environ Geol, 2009, Vol 58: 1727-1740.

[8] Kh Riitters, Rv O'neill, Ct Hunsaker, Jd Wickham, Dh Yankee 1, Sp Timmins, Kb Jones and Bl Jackson. A Factor Analysis of Landscape Pattern and Structure Metrics, Landscape Ecology, 1995, Vol. 10 (1 ): 23-39.

[9] Marit Vorkinn, Odd Inge Vistad, Jorid Vaagland. Tourist Experiences and Attractions, Annals Of Tourism Research, 2000, 27 (2): 432-450, 2000.

[10] Mcdermott \& Allyson. European Support For Historic Wallpapers, Icon News, 2008, Vol 16: 22-25. 